\title{
Purinergic Modulation of Cochlear Partition Resistance and Its Effect on the Endocochlear Potential in the Guinea Pig
}

\author{
Peter R. Thorne, ${ }^{1,2}$ David J. B. Muñoz, ${ }^{1,2}$ and Gary D. Housley ${ }^{2}$ \\ ${ }^{1}$ Discipline of Audiology, Faculty of Medical and Health Sciences, University of Auckland, Auckland, New Zealand \\ ${ }^{2}$ Department of Physiology, Faculty of Medical and Health Sciences, University of Auckland, Auckland, New Zealand
}

Received: 11 February 2003; Accepted: 8 August 2003; Online publication: 13 October 2003

\section{ABSTRACT}

Introduction of adenosine $5^{\prime}$-triphosphate (ATP) into the endolymphatic compartment of the guinea-pig cochlea decreases the endocochlear potential (EP). To determine if this is due to an ATP-induced change in compartment resistance, the cochlear partition resistance (CoPR) was measured using constant current injections into scala media before, during, and after microinjection of ATP into the same compartment. The CoPR $($ mean $=3.13 \pm 0.13 \mathrm{k} \Omega$ ) decreased with ATP in a dose-dependent manner $(25.1 \pm 3.0 \%$ decrease in relation to baseline values) and this was linearly correlated $\left(R^{2}=0.91\right)$ to the magnitude of the ATP-induced decline in EP $(41.6 \pm 7.0 \%$ decline in relation to the baseline). Pyridoxalphosphate-6azophenyl-2',4'-disulfonic acid (PPADS, a P2X receptor antagonist) injected prior to ATP application blocked this ATP-induced reduction in EP and CoPR. This indicates that ATP-gated ion channels (P2X receptors) provide a latent shunt capable of regulating the majority of the electrical potential across the luminal surface of the sensory hair cells, which is necessary for sound transduction. The results suggest a novel sound transduction regulatory mechanism, which, via extracellular ATP, has the capability of adjusting hearing sensitivity.

\footnotetext{
Correspondence to: Peter R. Thorne, Ph.D. - Discipline of Audiology • Faculty of Medical and Health Sciences - University of Auckland • Private Bag 92019 - Auckland - New Zealand. Telephone: (64 9) 3737599; fax: (64 9) 3737496; email: pr.thorne@auckland.ac.nz
}

Keywords: adenosine triphosphate, cochlea, cochlear function, cochlear partition resistance, endocochlear potential, $\mathrm{P} 2$ receptors

\section{INTRODUCTION}

Identification of $\mathrm{P} 2$ receptor subtypes in the mammalian cochlea supports the view that extracellular adenosine 5 -triphosphate (ATP) plays a role in the regulation of cochlear function. One important role may be in the regulation of the sound transduction process and thus cochlear sensitivity (Thorne and Housley 1996; Housley 1998; Housley et al. 1999, 2002; Housley and Thorne 2000). Essential to sound transduction is the large $(100-170 \mathrm{mV})$ electrochemical driving force across the luminal surface of the organ of Corti, provided by the positive endocochlear potential $(\mathrm{EP} ;+60$ to $+100 \mathrm{mV})$ and the negative resting membrane potential of the inner (IHC) and outer (OHC) hair cells $(-40 \mathrm{mV}$ and -70 $\mathrm{mV}$, respectively) (Dallos 1985). Interestingly, the introduction of ATP into the endolymphatic compartment causes a reversible decline in the EP in a dose-dependent manner (Muñoz et al. 1995, 1999; Kirk and Yates 1998). Pharmacological studies indicate that this is likely to be via activation of ATP-gated ion channels assembled mainly from $\mathrm{P}_{2} \mathrm{X}_{2}$ receptor subunits (Muñoz et al. 1999) localized to cells lining the compartment (Housley et al. 1992, 1998, 1999; Mockett et al. 1994; King et al. 1998; Housley and Thorne 2000), particularly the hair cells and 
supporting cells of the organ of Corti and cells of Reissner's membrane. Evidence of free ATP in the endolymph under normal conditions and elevation of fluid ATP concentration with noise and hypoxia (Muñoz et al. 2001) implies that endogenous ATP may affect EP under normal and stress conditions. Under this model, the ATP-gated conductance across the cells lining the endolymphatic compartment would regulate the driving force available for sound transduction by the hair cells.

To test this hypothesis we have studied the influence of exogenous ATP on the resistance of the endolymphatic compartment (defined here as the cochlear partition resistance, CoPR). Here we demonstrate that ATP reduces the CoPR. We propose that this arises from a shunt conductance that short- circuits the endocochlear potential and, coupled with the direct action of ATP to depolarize the hair cells, leads to a significant compression in the electrochemical driving force for sound transduction.

\section{METHODS}

Methods were approved by the University of Auckland Animal Ethics Committee. Guinea pigs were anesthetized with $60 \mathrm{mg} / \mathrm{kg}$ IP Nembutal ${ }^{\mathrm{TM}}$ and artificially ventilated with room air. End-tidal $\mathrm{O}_{2}$ and $\mathrm{CO}_{2}$ and blood pressure were monitored continuously. The cochlea was exposed and holes (40-100 $\mu \mathrm{m}$ in diameter) were made in the bone overlying the scala media and scala tympani of the basal turn to insert micropipettes for EP and CoPR measurements, and for current injection (Fig. 1A).

A double-barreled glass micropipette was inserted into scala media for voltage measurement (EP) and to inject ATP. A single-barreled micropipette was inserted into scala media through an adjacent hole to deliver current. The voltage and current pipettes, each coupled to a Teflon ${ }^{\circledR}$-coated $\mathrm{Ag}-\mathrm{AgCl}$ wire, were filled with artificial endolymph and were separated by $0.4-$ $0.5 \mathrm{~mm}$. Two Teflon ${ }^{\circledR}$-coated $\mathrm{Ag}-\mathrm{AgCl}$ wires were placed in holes in scala tympani $(0.7-0.8 \mathrm{~mm}$ separation) adjacent $(0.8-0.9 \mathrm{~mm}$ equidistant) to the scala media electrodes to serve as ground references for the voltage measurement and current injection (Fig. 1A). Different volumes (see below) of ATP $(100 \mu \mathrm{M})$ contained in artificial endolymph were microinjected into scala media using computer-controlled pressure pulses to produce declines in EP of different magnitude, as reported previously (Muñoz et al. 1995, 1999).

To ensure proper positioning of the current micropipette within scala media, EP was monitored as the pipette was advanced and, once a stable value was obtained, the electrode was connected to the current source. Current was generated by a two-electrode voltage clamp amplifier (GeneClamp 500, Axon Instruments, Union City, CA, USA) or a custom-made constant current injector controlled by a D/A converter (TL-1, Scientific Solutions Inc., Mentor, OH, USA) using pClamp software (pClamp 5.5, Axon Instruments). Square current pulses ( $1 \mu \mathrm{A}, 3 \mathrm{~s}$ duration at $6 \mathrm{~s}$ intervals) were continuously applied to the scala media electrode, with the ground electrode in scala tympani. ATP was then injected into scala media for $60 \mathrm{~s}$ to produce a steady-state reduction in EP (Fig. 1B). As the extent of the ATP-induced reduction in EP is dose-dependent (Muñoz et al. 1995, 1999), the total amount of ATP injected was varied across experiments by changing the pressure to the injection pipette to produce a reduction in EP of different magnitudes. The total volume of ATP solution applied varied across experiments from 250 to $1000 \mathrm{nl}$ (equivalent to $2.5 \times 10^{-11}$ and $10 \times 10^{-11} \mathrm{~mol}$ ). In another group of experiments, the $\mathrm{P} 2 \mathrm{X}$ receptor antagonist pyridoxalphosphate-6-azophenyl-2', $4^{\prime}$-disulfonic acid (PPADS, $1 \mathrm{mM}$ in artificial endolymph, 50 nl) was injected through the voltage-sensing micropipette prior to the ATP pulse. The effect of this postPPADS ATP pulse on EP and CoPR was compared with the effect produced by a pre-PPADS ATP pulse of the same amount (baseline). Control experiments were performed in the same manner, using similar volumes of either artificial endolymph without ATP (250-1000 nl) or with PPADS (1 mM, $50 \mathrm{nl})$.

Current-induced voltage shifts in EP were measured before, during, and after the ATP and control pulses (pClamp software) and used to calculate the CoPR $\left(R=\Delta V_{\mathrm{EP}} / I\right)$. A minimum of three CoPR values were averaged to provide each CoPR data point. Although EP can range from positive to negative (under anoxia) values, in these studies, the percentage change in EP assumed a 0 (zero) $\mathrm{V}$ reference. EP changes in percentage were calculated relative to the initial EP measurement before the test or control pulses. Results were expressed as the mean \pm standard error of the mean. Because insertion of the multiple electrodes into scala media caused some tissue damage which often resulted in lower EP values, only experiments with EP values $\geq 55 \mathrm{mV}$ were accepted.

To assess the influence of the loss of inner and outer hair cells on compartment resistance, a group of guinea pigs was injected with kanamycin (400 mg/ $\mathrm{kg}$ /day SC) for 14 days to induce hair cell degeneration. These animals were then treated in the same way as the normal guinea pigs with measurements of the CoPR. The cochleae were collected and processed for light microscopy to assess cochlear pathology. Cochleae were fixed by intralabyrinthine perfusion with $2.5 \%$ glutaraldehyde in $0.08 \mathrm{M}$ phosphate buffer, decalcified in $4 \%$ EDTA (with $0.5 \%$ glutaraldehyde), dehydrated in a graded series of 

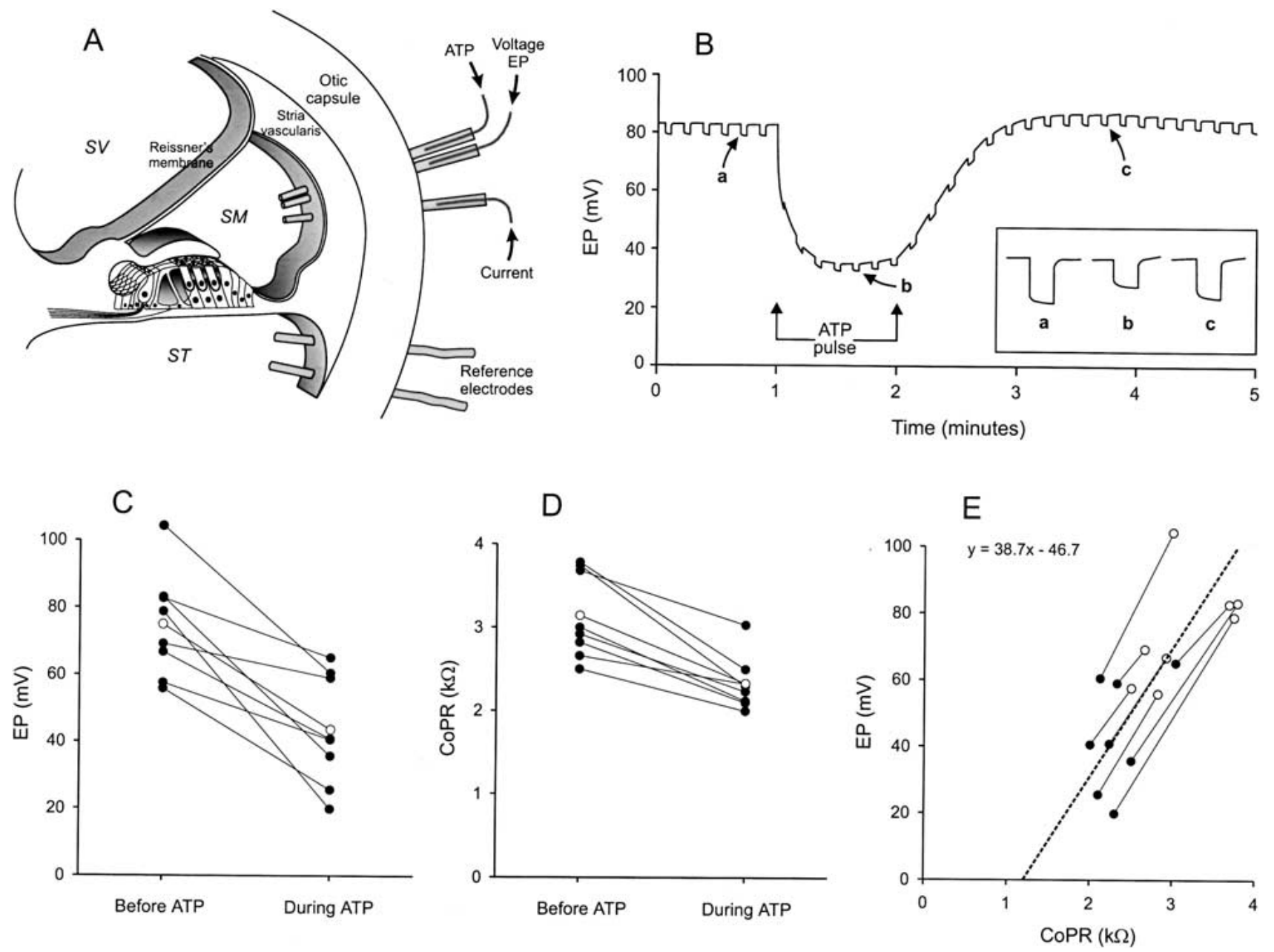

FIG. 1. A. Diagram showing the arrangement for microinjection of ATP into scala media and measurement of EP and CoPR. SV = scala vestibuli, $\mathrm{SM}=$ scala media, $\mathrm{ST}=$ scala tympani. B. An example of ATP-induced reduction in CoPR. ATP (500 nl, $100 \mu \mathrm{M}$, applied over $1 \mathrm{~min}$ ) reduced $\mathrm{EP}$ from 83 to $36 \mathrm{mV}$ concomitant with a reduction in the magnitude of the $1 \mu \mathrm{A}$ current-induced voltage shift $(3 \mathrm{~s})$ from $3.8 \mathrm{mV}$ (arrow a) to $2.5 \mathrm{mV}$ (arrow b), corresponding to a decrease of CoPR from $3.8 \mathrm{k} \Omega$ to $2.5 \mathrm{k} \Omega$, respectively. After ATP injection, CoPR returned to baseline levels (arrow c). The inset shows the voltage

ethanol solutions, and then embedded in epoxy resin. The entire cochlea was sectioned axially (1-2 $\mu \mathrm{m}$ thick) and every 20th section was mounted on glass slides, stained with $1 \%$ toluidine blue, and studied by light microscopy. The condition of the organ of Corti in different turns of the cochlea was noted in each section.

\section{RESULTS}

\section{Effect of ATP on EP and CoPR}

A mean baseline $\mathrm{EP}$ of $74.8 \pm 5.6 \mathrm{mV}(n=8)$ was recorded from the first cochlear turn of normal guinea pigs. Similar to our previous findings (Muñoz et al. 1995, 1999), ATP introduced into the endo-

lymphatic space at varying amounts $(100 \mu \mathrm{M}$ in 250 $1000 \mathrm{nl}$ solution volume) caused a significant ( $p=$ 0.0013 , paired Student's $t$-test) dose-related decline in the EP. The decrease in EP ranged from 10.2 to 58.9 $\mathrm{mV}$ (mean $=31.4 \pm 6.0 \mathrm{mV}, n=8$; Fig. 1C), which was a $41.6 \pm 7.0 \%$ reduction of the original EP. The EP reached a steady state during the ATP application, and, after cessation of the ATP pulse, it always recovered fully to the baseline (Fig. 1B). The introduction of the same volumes of artificial endolymph without ATP had no significant effect on EP (see Control experiments subsection below).

The current injection prior to the introduction of ATP produced a reduction in the EP of $2.5-3.8 \mathrm{mV}$ with a similar time constant (400-500 ms) to previous studies (Johnstone et al. 1966). These changes in 
A

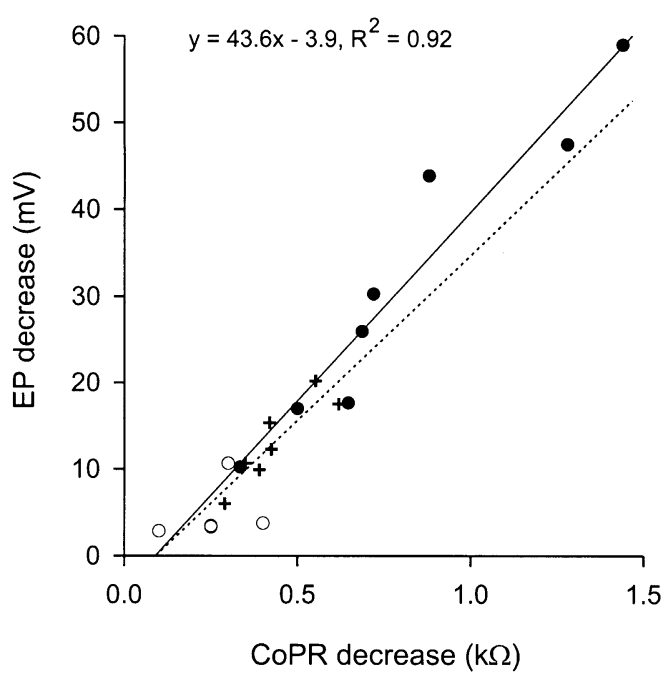

CoPR decrease $(\mathrm{k} \Omega)$

FIG. 2. Relationship between the magnitude of the ATP-induced reduction $(\mathbf{A})$ or percentage reduction $(\mathbf{B})$ in EP and CoPR (filled circles). For comparison, open circles in $\mathbf{A}$ and $\mathbf{B}$ represent the relationship of the EP and CoPR changes induced by ATP when applied after PPADS (from the PPADS subset of experiments). Crosses

voltage translate into a baseline CoPR of $2.5-3.8 \mathrm{k} \Omega$ (mean $=3.14 \pm 0.18 \mathrm{k} \Omega, n=8$ ) which is in agreement with previous estimates for a similar separation between the voltage and current injection pipettes $(3.37 \pm 0.154 \mathrm{k} \Omega)$ (Asakuma et al. 1978). The CoPR decreased significantly $(p<0.001$, paired Student's $t$ test, $n=8)$ to $2.0-3.0 \mathrm{k} \Omega$, $($ mean $=2.3 \pm 0.11 \mathrm{k} \Omega)$ (Fig. 1D) during the introduction of ATP, which was a reduction by $25.1 \pm 3.0 \%$ of the original resistance. This decrease in CoPR occurred in each experiment and was proportional to the magnitude of the fall in EP (Fig. 1E). CoPR returned to the baseline values upon full recovery of EP (Fig. 1B).

Assuming a linear relationship between EP and CoPR, projection of the individual curves in Figure IE to the $x$-axis provides an estimate of the magnitude of the resistance components in the compartment that are not affected by ATP. The magnitude of the mean residual compartment resistance when $\mathrm{EP}$ is $0 \mathrm{mV}$, as shown by the intercept in Figure 1E, was $1.092 \pm 0.17$ $\mathrm{k} \Omega$, which is approximately one-third of the resting CoPR; thus, two thirds of the CoPR can be lost when endolymphatic ATP is elevated.

Linear regression analysis showed a significant linear correlation $\left(\right.$ slope $=43.6 \mathrm{mV} / \mathrm{k} \Omega, R^{2}=0.92$; ANOVA $\left.F_{(1,6)}=70.3, p=0.0002\right)$ between the ATPinduced change in CoPR and the fall in EP (Fig. 2A). Analysis of the data as a percentage change in CoPR and EP voltage relative to baseline measurements (Fig. 2B). showed a similar linear relationship (slope $=2.2, \quad R^{2}=0.91 ; \quad$ ANOVA $F_{(1,6)}=58.8, \quad p=$ $0.0003)$.
B

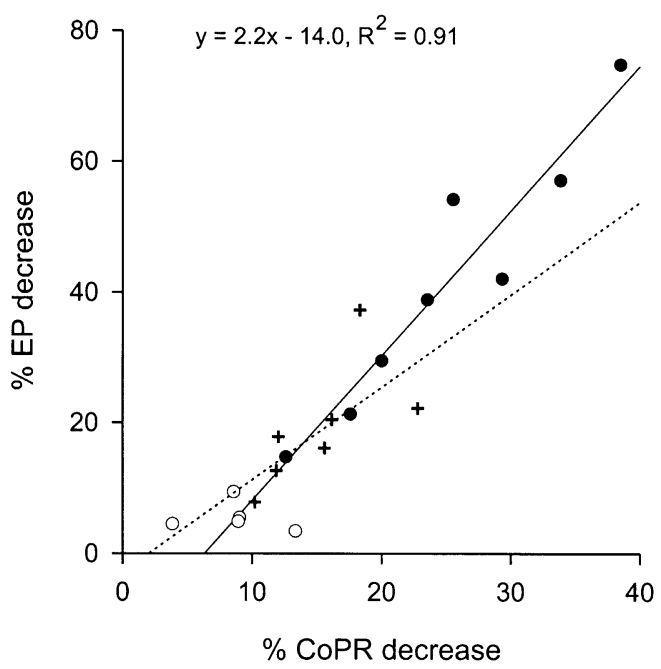

in $\mathbf{A}$ and $\mathbf{B}$ represent the data from kanamycin-treated animals from which the dotted linear regression lines were produced for comparison (see text). Solid linear regression lines and equations apply only to data represented by the filled circles.

Effect of PPADS and kanamycin on ATP-induced changes in EP and CoPR

A separate set of experiments was undertaken to investigate the influence of the $\mathrm{P} 2 \mathrm{X}$ receptor antagonist PPADS on the ATP-induced changes in EP and CoPR. In these experiments, ATP $(100 \mu \mathrm{M}$ in $500 \mathrm{nl})$ significantly $(p=0.0014$, Student's paired $t$-test $)$ reduced the magnitude of the EP from a baseline level of $82.3 \pm 9.0 \mathrm{mV}$ to $48.8 \pm 4.8 \mathrm{mV}(40.4 \pm 0.7 \%$ decrease, $n=5)$ (Fig. 3A). Similarly, the CoPR decreased $(p<0.001$, Student's paired $t$-test $)$ from a baseline of $2.9 \pm 0.06 \mathrm{k} \Omega$ to $2.1 \pm 0.05 \mathrm{k} \Omega(26.4 \pm$ $1.3 \%$ decrease, $n=5$ ) (Fig. 3B). In contrast, a second pulse of the same amount of ATP $(100 \mu \mathrm{M}$ in $500 \mathrm{nl})$ applied after PPADS $(1 \mathrm{mM}, 50 \mathrm{nl})$ decreased EP by only $5.6 \pm 1.0 \%$ and CoPR by only $8.7 \pm 1.5 \%$ (Fig. 3A, B). Thus, PPADS significantly reduced the ATPinduced decline in EP by $86 \%(p<0.001, n=5$; paired Student's $t$-test) and the ATP-induced decline in CoPR by $67 \%(p<0.001, n=5$; paired Student's $t$-test $)$ (Fig. 3A, B).

The kanamycin-treated animals had a mean EP of $71.5 \pm 4.5 \mathrm{mV}$ and a mean baseline CoPR (preATP) of $2.87 \pm 0.08 \mathrm{k} \Omega(\mathrm{n}=7)$, which was not significantly different ( $p=0.23$, non-paired Student's $t$ test) from the mean baseline CoPR in normal animals $(3.14 \pm 0.18 \mathrm{k} \Omega)$. ATP application induced a significant $(p<0.001$, paired Student's $t$-test, $n=7)$ fall in the CoPR to $2.44 \pm 0.10 \mathrm{k} \Omega$. The decrease in CoPR with ATP and the slope and intercept of the relationship between CoPR decrease and EP 
A

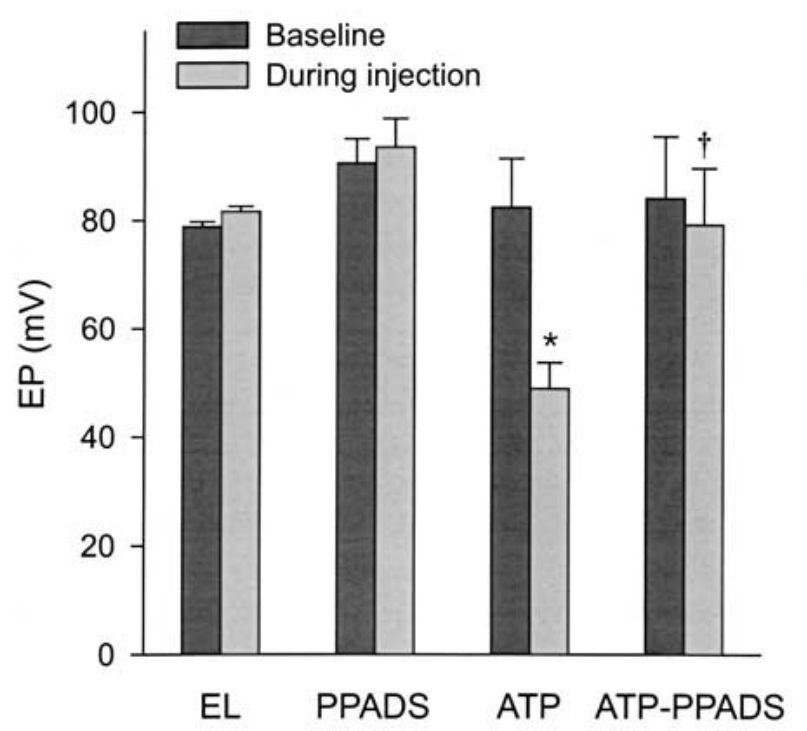

B

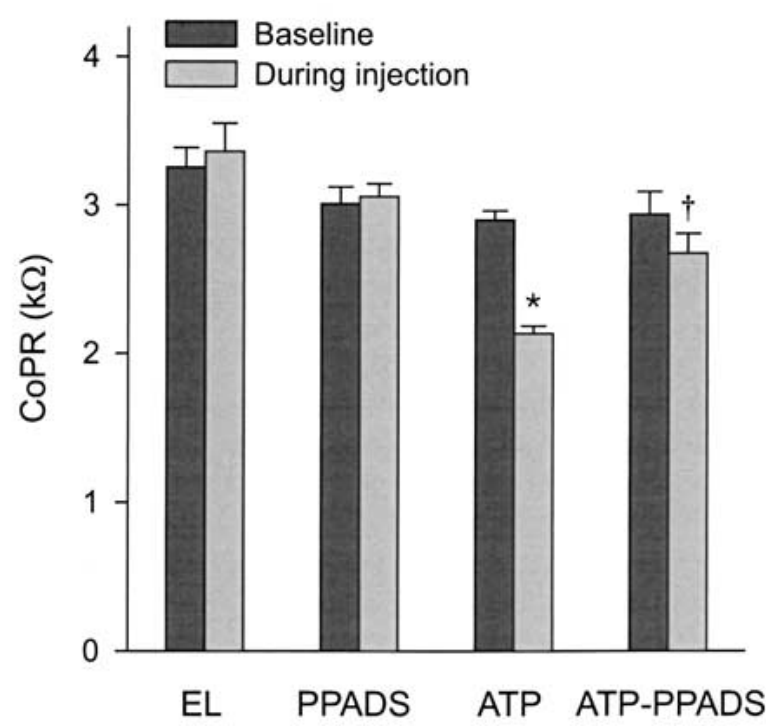

C

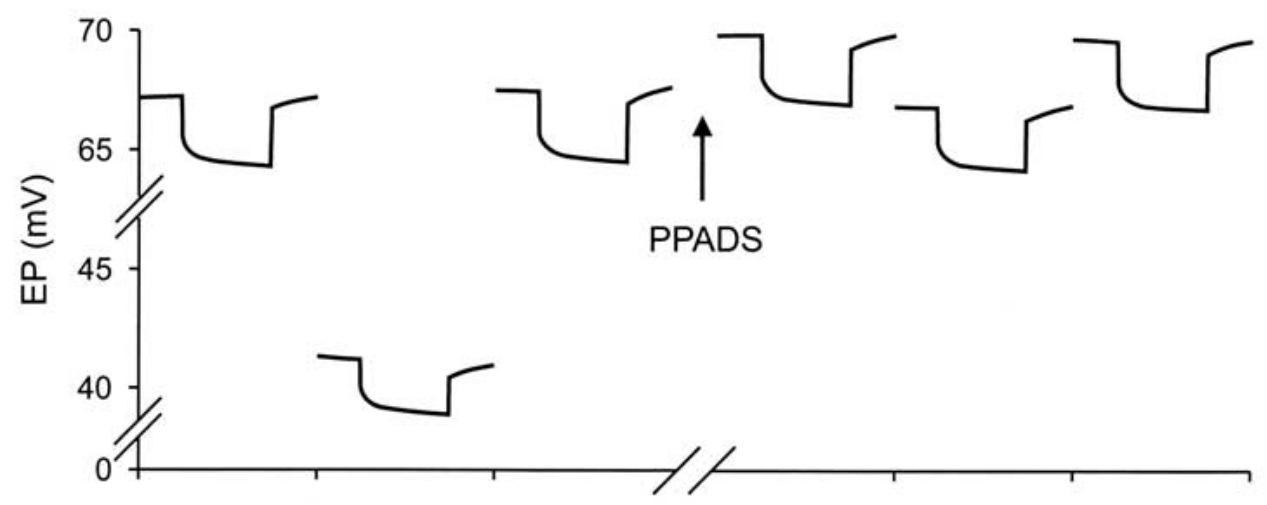

Before ATP During ATP After ATP

FIG. 3. Histograms showing the effect of artificial endolymph (EL), PPADS, ATP, and ATP following PPADS on the EP $(\mathbf{A})$ and COPR (B). Endolymph (mean of 250-1000 $\mathrm{nl}$ pulses) and PPADS (1 mM, $50 \mathrm{nl}$ ) control injections had a small effect on EP and CoPR. In contrast, ATP $(100 \mu \mathrm{M}$ in $500 \mathrm{nl})$ caused a significant decline in both measures $\left(^{*}, p=0.0014\right.$ and $p<0.001$, Student's paired $t$-tests for EP and CoPR, respectively), which was substantially reduced by the preapplication of PPADS ( $\dagger, p<0.001$, Student's paired $t$-tests for both EP and CoPR). C. Example showing that PPADS blocks the ATPinduced reduction in EP and CoPR. The initial $26 \mathrm{mV}$ fall in EP

decrease were not significantly different (ANOVA $F_{(1,11)}=0.12, p=0.73$ and $F_{(1,12)}=0.68, p=0.43$; slope and intercept, respectively) compared to the normal animals. Similarly, the difference was not significant when the data were measured as percent CoPR decrease and EP decrease (ANOVA $F_{(1,11)}=0.42, p=0.53$ and $F_{(1,12)}=0.25, p=0.63$; slope and intercept, respectively). Qualitative light microscopy showed the loss of both inner and outer sensory hair cells from the organ of Corti in the

\section{Before ATP During ATP After ATP}

observed during ATP pulse injection (from 67 to $41 \mathrm{mV}$ ) was reduced by prior application of PPADS to only a $3 \mathrm{mV}$ fall (from 70 to $67 \mathrm{mV}$ ). Concomitantly, the initial $0.7 \mathrm{k} \Omega$ fall in CoPR (calculated from 2.9 and $2.2 \mathrm{mV}$, the current-induced voltage shifts produced before and during ATP injection, respectively) induced by ATP was reduced to a $0.25 \mathrm{k} \Omega$ fall by PPADS pre-application (from 2.8 to $2.55 \mathrm{k} \Omega$ ). Both, EP and CoPR returned to baseline levels after the ATP pulse. Only one current-induced voltage shift is shown for each experimental stage for clarity. Data records were digitally reconstructed.

first and second turns of each of the kanamycintreated animals (Fig. 4) with degeneration of some of the supporting cells also in the first cochlear turn.

\section{Control experiments}

In control experiments, artificial endolymph without ATP $(250-1000 \mathrm{nl})$ or with PPADS $(50 \mathrm{nl})$ produced a small and transient increase in the EP. Endolymph 


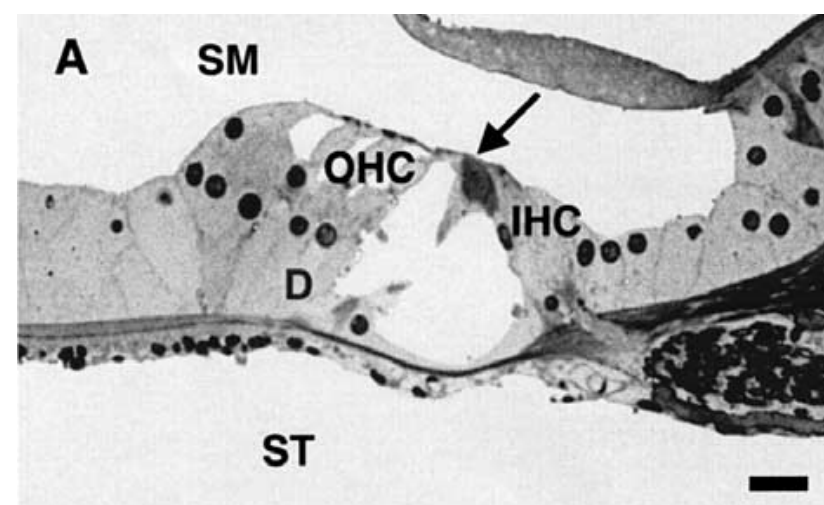

FIG. 4. Light microscopy of the organ of Corti from the first turn of normal (A) and kanamycin-treated (B) guinea pigs. The normal organ of Corti shows the three rows of outer sensory hair cells $(\mathrm{OHC})$, supported at their base by the Deiters' supporting cells (D) and separated by the supporting pillar cells (arrow) from a single row of inner sensory hair cells (IHC). The upper surface of the organ of Corti

produced an increase in $\mathrm{EP}$ of $2.8 \pm 0.9 \mathrm{mV}$ over a baseline of $78.8 \pm 0.9 \mathrm{mV}(n=6)$ and PPADS produced an increase of $2.9 \pm 0.9 \mathrm{mV}$ over a baseline of $90.5 \pm 4.5 \mathrm{mV}(n=8)$ (Fig. 3A). Similarly, a small transient increase in CoPR was observed with the application of both artificial endolymph without (ATP $0.11 \pm 0.06 \mathrm{k} \Omega$ over a baseline of $3.25 \pm 0.132$ $\mathrm{k} \Omega ; n=6)$ and with PPADS $(0.05 \pm 0.041 \mathrm{k} \Omega$ over a baseline of $3.0 \pm 0.11 \mathrm{k} \Omega ; n=8$ ) (Fig. 3B).

\section{DISCUSSION}

These data show that the endolymphatic ATP-mediated decline in EP (Muñoz et al. 1995, 1999) is strongly correlated with a decrease in the electrical resistance of the cochlear partition. This is indicative of an ATP-activated increase in ionic conductance through tissues lining the compartment. Because the ATP-induced reduction in CoPR is directly proportional to the magnitude of the ATP-induced fall in EP and was substantially blocked by the $\mathrm{P} 2 \mathrm{X}$ receptor antagonist PPADS, it is likely to be a direct result of an ATP-induced electrical shunt mediated by $\mathrm{K}^{+}$efflux through P2X receptors in cells lining the endolymphatic space. These findings support the view that a substantial proportion of the resistive component of the endolymphatic compartment that maintains the $\mathrm{EP}$ and hence the driving force for sound transduction is regulated by ATP-gated ion channels.

The baseline value of the EP was slightly lower than other previous reports of the magnitude of EP in the basal turn (80-100 mV) (e.g., Muñoz et al. 1999). This is probably due to tissue damage during the insertion of the multiple electrodes into the endolymphatic space. However, we have previously

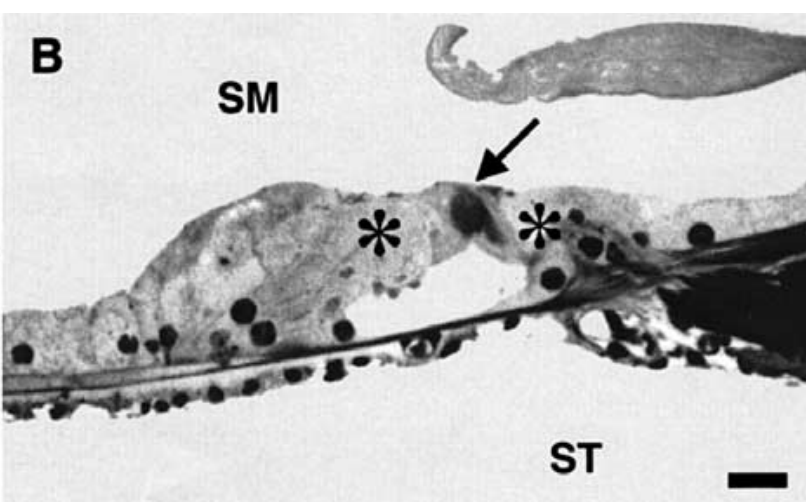

is bathed by endolymph of the scala media (SM) and the basal surface is bathed by perilymph in the scala tympani (ST). In contrast, after kanamycin treatment, both types of sensory cell are missing and the space is now occupied by expanded supporting cells (stars). The remaining pillar cells (arrow) define the original architecture. Scale bar $=20 \mu \mathrm{m}$.

demonstrated that the ATP-induced change in EP is proportional to the starting magnitude of EP $(\mathrm{Mu}-$ ñoz et al. 1995, 1999). Thus, the initial EP levels are unlikely to influence the nature of the change in the endolymphatic compartment resistance due to ATP.

Control experiments showed a small transient increase in the magnitude of the EP and the CoPR with either artificial endolymph or PPADS solution. The small increase in EP is similar to the findings of Kakigi and Takeda (1998) who injected up to $2 \mu$ l of artificial endolymph into scala media in guinea pigs. The increase in EP and CoPR may be due to a volume-induced downward shift of the basilar membrane (Tasaki et al. 1954), possibly affecting the silent current. This small EP increase shows that the effect of increasing endolymphatic volume, at least in the range used in this study, had limited effect on the scala media compartment and its surrounding tissues.

ATP-gated ion channels composed mainly of P2X receptor subunits are predominant in cells lining the endolymphatic compartment, including IHCs, OHCs, and Deiters' cells of the organ of Corti and cells of the Reissner's membrane (Housley et al. 1992, 1998, 1999; Mockett et al. 1994; King et al. 1998). These ion channels are non-selective for $\mathrm{Na}^{+}$and $\mathrm{K}^{+}$(Nakagawa et al. 1990) and when facing the unique environment of the scala media, with its high $\mathrm{K}^{+}$concentration (approximately $150 \mathrm{mM}$ ), activation under normal conditions would result in $\mathrm{K}^{+}$influx with current outflow via basolateral $\mathrm{K}^{+}$channels causing a decline in EP. The pharmacology of the ATP-induced fall in EP supports this P2X receptor-mediated mechanism (Muñoz et al. 1995, 1999). There is no evidence of ATP-gated ion channels in the cells of the guinea-pig stria vascularis (Housley et al. 1999), although in a 
number of species the marginal cells possess metabotropic P2Y receptors (Ogawa and Schacht 1995; Marcus et al. 1998; Sage and Marcus 2002).

The strong relationship between the ATP-induced change in CoPR and fall in EP implies that much of the changes in resistance across the cochlear partition can be obviated by a $\mathrm{P} 2 \mathrm{X}$ receptor-mediated conductance. However, clearly there are other resistive components as shown by the offset in intercepts in Figures $1 \mathrm{E}$ and $2 \mathrm{~A}$ and by the dissimilar blocking effect of PPADS on the ATP-mediated decrease in CoPR and EP (67\% and 86\% block, respectively). However, no conclusion can be drawn from this as some of the small variance in the relationship between EP and CoPR is also likely to be due to the spatial separation between the electrode and delivery pipette (Asakuma et al. 1978). Changes in EP at the recording electrode will be limited by the diffusion of ATP and PPADS from the delivery pipette. The observed ATP effect in the guinea pig is not likely to be due to P2Y receptors on the stria vascularis (Marcus et al. 1998) although in other species, such as the rat, P2Y activation could be expected to affect EP by inhibition of KCNQ1/KCNE1 $\mathrm{K}^{+}$channels on the marginal cells (Marcus et al. 1998; Jentsch 2000). However, this would be expected to have an inverse action on CoPR.

In the kanamycin-treated animals, the predominant removal of the hair cell component of the endocochlear shunt pathway had no significant effect on the ATP-induced fall in CoPR. This indicates that the hair cell $\mathrm{P} 2 \mathrm{X}$ receptor conductance contribution to this shunt is relatively small. Knowledge of the P2Xmediated conductances in various cell types of the cochlea allows an estimate of the contribution of different cochlear tissues to the total CoPR. Assuming that the ATP-activated conductance in our experiments principally involved the first turn of the cochlea, this would include approximately $360 \mathrm{OHCs}$ and 120 IHCs along each millimeter of organ of Corti (Thorne and Gavin 1984). In contrast, based on direct measurements of the Reissner's membrane (RM) area in the basal turn (Muñoz, personal communication) and an estimated Reissner's epithelial cell footprint of $71 \mu \mathrm{m}^{2}$ (King et al. 1998), we estimate that approximately $7042 \mathrm{RM}$ epithelial cells/mm would have been affected. Maximum P2X receptor conductances have been estimated for OHCs (127 nS) (Raybould and Housley 1997), IHCs (31 nS) (Raybould et al. 2001), and RM epithelial cells (37 nS) (King et al. 1998). Calculations of total tissue P2X-mediated contributions clearly indicate that the combined contribution of the hair cell ATP-activated shunt conductance in the region would be only approximately $19 \%$ of that derived from RM. In addition, other cells, such as the inner and outer sulcus cells, outer row Deiters' cells, and Hensen's cells, also provide large surface areas for the endocochlear P2X receptor conductance shunt (Housley et al. 1999; Lee et al. 2001). Thus, the final contribution of the hair cells to the ATP-mediated conductance is small, confirming the findings in kanamycin-treated animals. It should be noted, however, that the ATP-gated ion channels on the endolymphatic surface of the hair cells (Housley et al. 1999) provide a microshunt which would directly mitigate the driving force for the mechanoelectrical transducer conductance. Thus, the overall ATP-activated endocochlear shunt compresses the external driving force for the hair cell transducer conductance, and the hair cell $\mathrm{P} 2 \mathrm{X}$ receptor conductance compresses the internal driving force, while having negligible effect on the overall ATP-induced fall in EP.

This study provides direct evidence for a potent purine-mediated intrinsic homeostatic mechanism for regulating sound transduction by controlling the electrochemical driving force and hence sensitivity of the hearing process. Here, the electrical shunt conductance coupled to the ATP-mediated hair cell depolarization would combine to limit the electrochemical driving force responsible for sound transduction. The reduction in the receptor potential would affect the forward transduction mechanism through the IHC and OHC mechanoelectrical transduction (MET) channels and would also limit the active mechanical feedback in the OHC resulting in a reduction of sound-induced neurotransmission at the IHC.

In summary, these findings imply that extracellular purines are intrinsic mediators of cochlear homeostasis, regulating the sound transduction mechanism.

\section{ACKNOWLEDGMENTS}

This study was supported by the Deafness Research Foundation of New Zealand, the Auckland Medical Research Foundation, the Health Research Council of New Zealand, the New Zealand Lottery Grants Board, and the Garnett Passe and Rodney Williams Memorial Foundation. We thank Tania Billett for the microscopy and Mr. Greg Gamble from the Department of Medicine, University of Auckland, for assistance in statistical analysis.

\section{REFERENCES}

Asakuma S, Snow Jr JB, Murakami Y. Electrical resistance of the cochlear partition. Hear. Res. 1:25-30, 1978.

Dallos P. Response characteristics of mammalian cochlear hair cells. J. Neurosci. 5:1591-1608, 1985.

HousLey GD. Extracellular nucleotide signaling in the inner ear. Mol. Neurobiol. 16:21-48, 1998. 
Housley GD, Thorne PR. Purinergic signalling: an experimental perspective. J. Auton. Nerv. Syst. 81:139-145, 2000.

Housley GD, Greenwood D, Ashmore JF. Localization of cholinergic and purinergic receptors on outer hair cells isolated from the guinea-pig cochlea. Proc. R. Soc. Lond. B Biol. Sci. 249:265-273, 1992.

HousLey GD, Luo L, Ryan AF. Localization of mRNA encoding the $\mathrm{P}_{2} \mathrm{X}_{2}$ receptor subunit of the adenosine $5^{\prime}$-triphosphate-gated ion channel in the adult and developing rat inner ear by in situ hybridization. J. Comp. Neurol. 393:403-414, 1998.

Housley GD, Kanjhan R, Raybould NP, Greenwood D, Salih SG, Jarlebark L, Burton LD, Setz VC, Cannell MB, Soeller C, Christie DL, Usami S, Matsubara A, Yoshie H, Ryan AF, Thorne $\mathrm{PR}$. Expression of the $\mathrm{P}_{2} \mathrm{X}_{2}$ receptor subunit of the ATP-gated ion channel in the cochlea: implications for sound transduction and auditory neurotransmission. J. Neurosci. 19:8377-8388, 1999.

Housley GD, Jagger DJ, Greenwood D, Raybould NP, Salih SG, Jarlebark LE, Vlajkovic SM, Kanjhan R, Nikolic P, Muñoz DJB, THORNE PR. Purinergic regulation of sound transduction and auditory neurotransmission. Audiol. Neurootol. 7:55-61, 2002.

JENTSCH TJ. Neuronal KCNQ potassium channels: physiology and role in disease [review] [84 refs]. Nat. Rev. Neurosci. 1:21-30, 2000.

Johnstone BM, Johnstone JR, PugsLey ID. Membrane resistance in endolymphatic walls of the first turn of the guinea-pig cochlea. J. Acoust. Soc. Am. 40:1398-1404, 1966.

KAKIGI A, TAKEDA T. Effect of artificial endolymph injection into the cochlear duct on the endocochlear potential. Hear. Res. 116:113-118, 1998.

King M, Housley GD, Raybould NP, Greenwood D, Salih SG. Expression of ATP-gated ion channels by Reissner's membrane epithelial cells. Neuroreport 9:2467-2474, 1998.

KIRK DL, YATES GK. ATP in endolymph enhances electrically-evoked oto-acoustic emissions from the guinea pig cochlea. Neurosci. Lett. 250:149-152, 1998.

LeE JH, Chiba T, Marcus DC. P2X 2 receptor mediates stimulation of parasensory cation absorption by cochlear outer sulcus cells and vestibular transitional cells. J. Neurosci. 21:9168-9174, 2001.

Marcus DC, Sunose H, Liu J, Bennett T, Shen Z, Scofield MA, Ryan AF. Protein kinase $\mathrm{C}$ mediates $\mathrm{P}_{2 \mathrm{U}}$ purinergic receptor inhibi- tion of $\mathrm{K}^{+}$channel in apical membrane of strial marginal cells. Hear. Res. 115:82-92, 1998.

Mockett BG, Housley GD, Thorne PR. Fluorescence imaging of extracellular purinergic receptor sites and putative ecto-ATPase sites on isolated cochlear hair cells. J. Neurosci. 14:6992-7007, 1994.

Muñoz DJB, Thorne PR, Housley GD, Billett Te, Battersby JM. Extracellular adenosine $5^{\prime}$-triphosphate (ATP) in the endolymphatic compartment influences cochlear function. Hear. Res. 90:106-118, 1995.

Muñoz DJB, Thorne PR, Housley GD. P2X receptor-mediated changes in cochlear potentials arising from exogenous adenosine 5 'triphosphate in endolymph. Hear. Res. 138:56-64, 1999.

Muñoz DJB, Kendrick IK, Rassam M, Thorne PR. Vesicular storage of ATP in the guinea-pig cochlear lateral wall and concentrations of ATP in endolymph during sound exposure and hypoxia. Acta Otolaryngol. (Stockh.) 121:10-15, 2001.

Nakagawa T, Akaike N, Kimitsuki T, Komune S, Arima T. ATP-induced current in isolated outer hair cells of guinea pig cochlea. J. Neurophys. 63:1068-1074, 1990.

Ogawa K, Schacht J. P2Y purinergic receptors coupled to phosphoinositide hydrolysis in tissues of the cochlear lateral wall. Neuroreport 6:1538-1540, 1995.

Raybould NP, Housley GD. Variation in expression of the outer hair cell P2X receptor conductance along the guinea-pig cochlea. J. Physiol. 498:717-727, 1997.

Raybould NP, Jagger DJ, Housley GD. Positional analysis of guinea pig inner hair cell membrane conductances: implications for regulation of the membrane filter. J. Assoc. Res. Otolaryngol. 2:362-376, 2001.

SAGE CL, Marcus DC. Immunolocalization of $\mathrm{P}_{2} \mathrm{Y}_{4}$ and $\mathrm{P}_{2} \mathrm{Y}_{2}$ purinergic receptors in strial marginal cells and vestibular dark cells. J. Membr. Biol. 185:103-115, 2002.

TASAKi I, Davis H, Eldredge DH. Exploration of cochlear potentials in guinea pig with microelectrode. J. Acoust. Soc. Am. 26:765$773,1954$.

Thorne PR, Gavin JB. The accuracy of hair cell counts in determining distance and position along the organ of Cord. J. Acoust. Soc. Am. 76:440-442, 1984.

Thorne PR, Housley GD. Purinergic signalling in sensory systems. Semin. Neurosci. 8:233-246, 1996. 